\title{
Hijacking of Basic Research: The Case of Synthetic Cannabinoids
}

Jenny L. Wiley, Julie A. Marusich, John W. Huffman, Robert L. Balster, and Brian F. Thomas

November 2011 


\section{About the Authors}

Jenny L. Wiley, PhD, is a senior behavioral pharmacologist in

RTI International's Discovery and

Analytical Sciences unit.

Julie A. Marusich, $\mathrm{PhD}$, is a research pharmacologist at RTI, where she works as part of the behavioral pharmacology team, focusing on the behavioral effects of drugs of abuse.

John W. Huffman, PhD, is a professor emeritus of chemistry at Clemson University in South Carolina.

Robert L. Balster, PhD, is director of the Institute for Drug and Alcohol Studies and a professor in the Department of Pharmacology and Toxicology, Virginia Commonwealth University, Richmond, Virginia.

Brian F. Thomas, PhD, is senior director of Analytical Chemistry and Pharmaceutics at RTI International.
This publication is part of the RTI Research Report series. Occasional Papers are scholarly essays on policy, methods, or other topics relevant to RTI areas of research or technical focus.

RTI International

3040 Cornwallis Road

PO Box 12194

Research Triangle Park, NC

27709-2194 USA

Tel: $\quad+1.919 .541 .6000$

Fax: $\quad+1.919 .541 .5985$

E-mail: rtipress@rti.org

Web site: www.rti.org

\section{RTI Press publication OP-0007-1111}

This PDF document was made available from www.rti.org as a public service of RTI International. More information about RTI Press can be found at http://www.rti.org/rtipress.

RTI International is an independent, nonprofit research organization dedicated to improving the human condition by turning knowledge into practice. The RTI Press mission is to disseminate information about RTI research, analytic tools, and technical expertise to a national and international audience. RTI Press publications are peer-reviewed by at least two independent substantive experts and one or more Press editors.

\section{Suggested Citation}

Wiley, J. L., Marusich, J. A., Huffman, J. W., Balster, R. L., \& Thomas, B. F. (2011). Hijacking of basic research: The case of synthetic cannabinoids. RTI Press publication No. OP-0007-1111. Research Triangle Park, NC: RTI Press. Retrieved from http://www.rti.org/rtipress.
(C)2011 Research Triangle Institute. RTI International is a trade name of Research Triangle Institute.

All rights reserved. This report is protected by copyright. Credit must be provided to the author and source of the document when the content is quoted. Neither the document nor partial or entire reproductions may be sold without prior written permission from the publisher.

doi:10.3768/rtipress.2011.op.0007.1111

www.rti.org/rtipress 


\section{Hijacking of Basic Research: The Case of Synthetic Cannabinoids}

\author{
Jenny L. Wiley, Julie A. Marusich, John W. Huffman, \\ Robert L. Balster, and Brian F. Thomas
}

Contents
$\begin{aligned} & \text { Introduction } \\ & \text { The Hijacking }\end{aligned}$
$\begin{aligned} & \text { Herbal Incense and } \\ & \quad \text { Its Regulation }\end{aligned}$
$\begin{aligned} & \text { Origins of the Synthetic } \\ & \quad \text { Cannabinoids in Herbal } \\ & \quad \text { Incense }\end{aligned}$
$\begin{aligned} & \text { Previous Cases of Designer } \\ & \quad \text { Drugs }\end{aligned}$
$\begin{aligned} & \text { Clinical Effects of Synthetic } \\ & \quad \text { Cannabinoids }\end{aligned}$
$\begin{aligned} & \text { Research Needed } \\ & \text { Concluding Remarks }\end{aligned}$
$\begin{aligned} & \text { References } \\ & \text { R }\end{aligned}$

Acknowledgments Inside back cover

\footnotetext{
Abstract

Gathering and communicating knowledge are important aspects of the scientific endeavor. Yet presentation of data in public forums such as scientific meetings and publications makes it available not only to scientists, but also to others who may have different ideas about how to use research findings. A recent example of this type of hijacking is the introduction of synthetic cannabinoids that are sprayed on herbal products and subsequently smoked for their marijuanalike intoxicating properties. Originally developed for the legitimate research purpose of furthering understanding of the cannabinoid system, these synthetic cannabinoids are being abused worldwide, creating issues for regulatory and law enforcement agencies that are struggling to keep up with the growing number of compounds of various structural motifs. Basic and clinical scientists need to provide advice now to facilitate decision-making about the health threats posed by this emerging problem.
} 


\section{Introduction}

Work as a bench scientist often involves long hours spent in a laboratory, talking with other scientists and having little contact with the outside world. Under these circumstances, losing sight of potential applications in the "real" world is easy-until an external event occurs that serves as a reminder that the work of scientists is not done in isolation. This paper presents a case study of the hijacking of findings from basic research on cannabinoids and the use of them to create products that may harm human health. This situation provides a valuable perspective on cannabinoid chemistry and its potential impact on human health and behavior. Further, examination of this situation highlights opportunities for research related to health issues caused by the new products.

\section{The Hijacking}

The story starts with John Huffman, professor emeritus of chemistry at Clemson University in South Carolina. After graduating with a doctorate in chemistry from Harvard University, Huffman accepted a faculty position at Clemson and spent much of his career following a traditional academic scientist path of teaching chemistry to graduate and undergraduate students while maintaining a grantsupported program of research. His major research area involved the synthesis of novel cannabinoids, drugs that possessed some of the properties of $\Delta^{9}$-tetrahydrocannabinol (THC), the main psychoactive constituent of cannabis.

A few years ago, Huffman began receiving phone calls from law enforcement agencies, the military, and panicked parents, a situation that has continued since his retirement at the end of September 2010. The cause of this consternation was JWH-018, one of the cannabinoids Huffman designed and synthesized in his laboratory, because forensic scientists had identified it in herbal mixtures being marketed over the Internet as incense. Rather than using these herbal blends (e.g., Spice Gold, Spice Diamond, Purple Haze, K2, Skunk, and Smoke; see Figure 1) as incense, people were apparently smoking them for their marijuana-like effects (Vardakou, Pistos, \& Spiliopoulou, 2010).
Figure 1. Purple Haze is one of the many herbal incense products containing synthetic cannabinoids

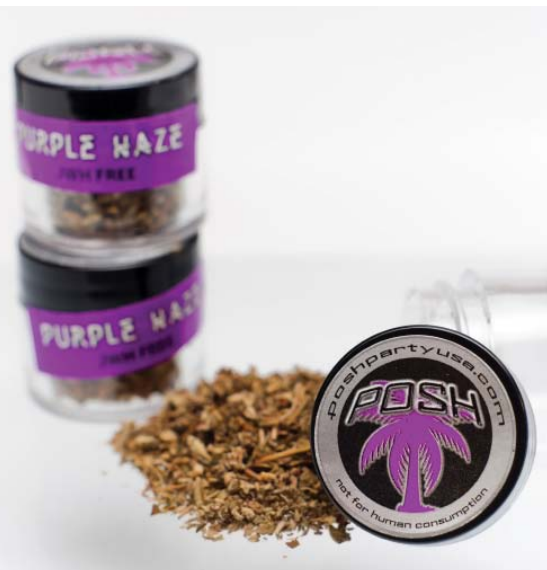

\section{Herbal Incense and Its Regulation}

While the packaging for these products lists only natural herbs as ingredients, analysis has revealed that they contain synthetic cannabinoids, including JWH-018, JWH-073, CP 47,497 (a bicyclic cannabinoid), and HU-210 (a tetrahydrocannabinol cannabinoid) (Auwarter et al., 2009; Lindigkeit et al., 2009; Teske et al., 2010; Uchiyama, Kikura-Hanajiri, Ogata, \& Goda, 2010). With the exception of HU-210, the cannabinoid constituents of these herbal blends are structurally distinct from THC and, until recently, were not treated as controlled substances in most states in the United States. Hence, they provided an alternative to cannabis for people seeking to avoid potential legal consequences of marijuana use or for those wanting to become intoxicated and still pass a drug test.

As knowledge of the intoxicating effects of these herbal products spread over the Internet, their use in the United States increased to the point that the Drug Enforcement Agency (DEA) issued an emergency edict late in November 2010 proposing to place JWH-018 and four related compounds under Schedule I control (DEA, 2010). The final order (effective March 1, 2011) made these drugs, and products that contain them, illegal to manufacture or possess without a Schedule I license. 
Groups of retailers are contesting this rule (see, for example, L.P.O.E., Inc. v. United States Drug Enforcement Administration, 2010) because the products are labeled "not for human consumption." Enforcement is difficult due, in part, to the widespread availability of the products and the insufficient manpower of enforcement agencies. For example, in an unsystematic survey, we found at least one of the banned substances in products we purchased in North Carolina after this new regulation became effective (Cox et al., in press).

In Europe, where use of synthetic cannabinoids in herbal preparations was first seen in 2006 (European Monitoring Centre for Drugs and Drug Addiction [EMCDDA], 2009), several countries have already banned the sale and use of JWH-018 and similar synthetic cannabinoids. While these actions will undoubtedly help restrict access to the cannabinoids covered under these regulations, hundreds of compounds, in several chemical classes, have good cannabinoid receptor affinity and activity, and new substances will likely continue to appear in various formulations intended for use as intoxicants.

Thus, the situation presents a constant challenge for scientists tasked with the forensic and toxicological identification of new synthetic cannabinoid substances or formulations, as well as for public health and law enforcement agencies responsible for the rapid assessment of risk and, where necessary, implementation of control measures.

As one step in this process, RTI International forensic scientist Peter Stout and his team have set up a searchable forensic database (https://www.forensicdb. org/index.htm) into which they are entering results of analysis of some of the original JWH compounds synthesized by Huffman (and provided by Jenny Wiley, a coauthor of this paper). This database is publically available to forensic scientists. One of the coauthors, Brian Thomas, and his RTI colleague Megan Grabenauer are also taking an active role in analyzing these compounds.

\section{Origins of the Synthetic Cannabinoids in Herbal Incense}

Although the abuse of JWH indole-derived cannabinoids is relatively recent, the original design of many of the compounds occurred more than 20 years ago. Publication of a report on a compound known as pravadoline served as a catalyst for work that eventually led to the creation of the synthetic cannabinoids recently proposed for control by the DEA. Synthesized by scientists at SterlingWinthrop, pravadoline exhibited promising analgesia preclinically with a mechanism distinct from opioid agonism or cyclooxygenase inhibition (Haubrich et al., 1990).

Researchers later found pravadoline to be nephrotoxic (Everett et al., 1993). In an effort to determine the mechanism through which it worked, researchers designed and synthesized conformationally restrained aminoalkylindole analogs (D'Ambra et al., 1992). From this program, researchers discovered WIN 55,212-2 to be a relatively potent analgesic, but Sterling-Winthrop dropped its research on aminoalkylindoles when it became clear that WIN 55,212-2 and related analogs were cannabimimetic (Compton, Gold, Ward, Balster, \& Martin, 1992; Eissenstat et al., 1995).

By then, however, the $\mathrm{CB}_{1}$ receptor had been identified (Devane, Dysarz, Johnson, Melvin, \& Howlett, 1988), and researchers initiated efforts to further explore the structural requirements of cannabinoid receptor binding (Martin et al., 1991). The findings that WIN55,212 2, CP55,940 (a synthetic bicyclic compound), and anandamide possessed cannabinoid activity in vivo emphasized the broad structural diversity of cannabinoid agonists.

Within this innovative milieu, Huffman hypothesized that the position of the morpholinoethyl group of WIN55,212-2 might overlay the C3 side chain of THC in the then-accepted 3-point attachment model of cannabinoid receptor binding (Huffman, Dai, Martin, \& Compton, 1994; Thomas, Compton, Martin, \& Semus, 1991). Based on this model, he and his league of student chemists at Clemson synthesized 
cannabinoids with comparable carbon chains attached to the nitrogen in the indole substituent (Huffman, Dai, Martin, \& Compton; Figure 2). They then sent the compounds to pharmacologists Billy Martin and Jenny Wiley at Virginia Commonwealth University (VCU) in Richmond, Virginia, for in vitro and in vivo evaluation.

Subsequent studies reported an orderly structureactivity relationship between structural variation in these molecules (e.g., length and branching of the chain) and binding to the two identified cannabinoid receptors, $\mathrm{CB}_{1}$ and $\mathrm{CB}_{2}$ (Aung et al., 2000; Huffman,
Dai, Martin, \& Compton; Lainton, Huffman, Martin, \& Compton, 1995).

$\mathrm{CB}_{1}$ receptors are the predominant type found in the brain and have been shown to mediate the intoxicating effects of THC in humans and in animal models (Huestis et al., 2001; Wiley, Lowe, Balster, \& Martin, 1995). Use of synthetic cannabinoids such as those synthesized by Huffman's group has vastly increased scientific knowledge of the characteristics of the interaction between cannabinoids and their receptors. This type of knowledge garnered from basic research has led to greater understanding of the

Figure 2. Chemical structures of THC, the aminoalkylindole WIN55,212-2, and some of the synthetic cannabinoids identified in herbal incense products

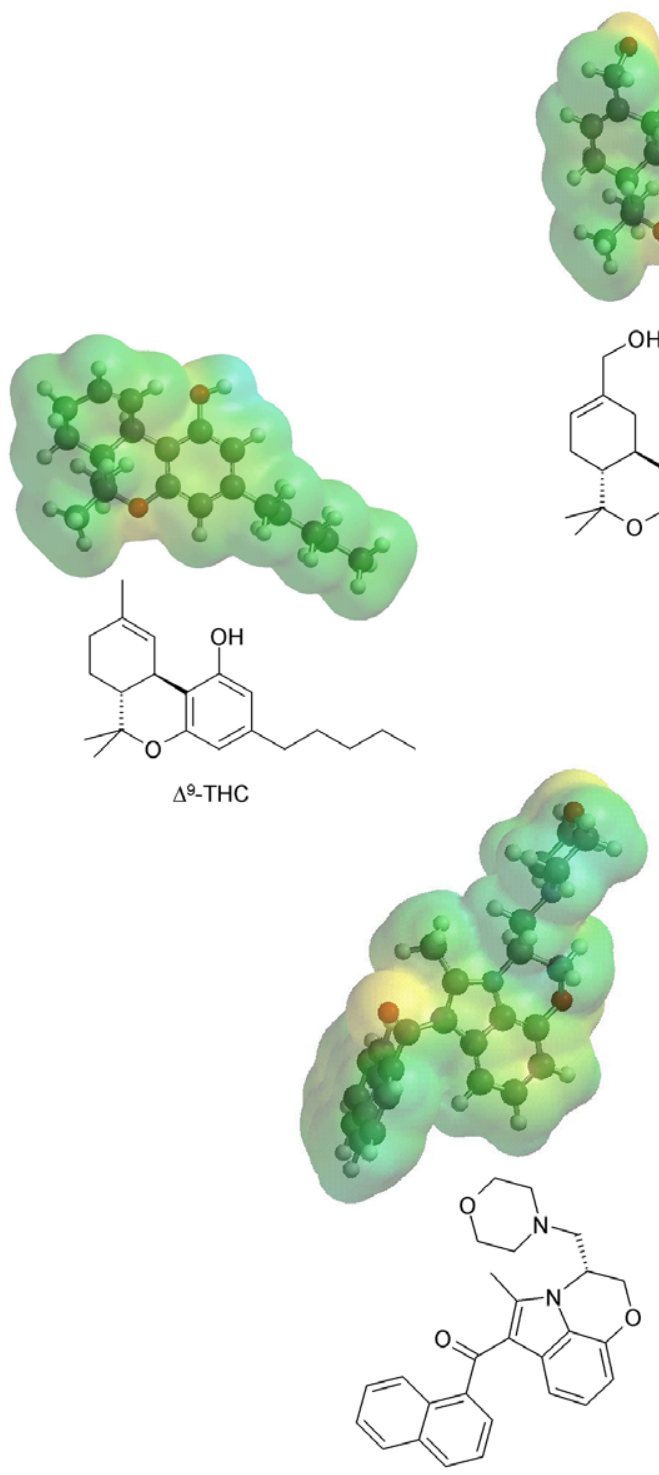

WIN 55212-2

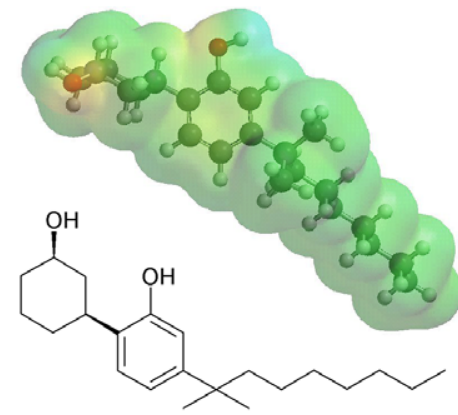

CP-47,497 Octyl Analog

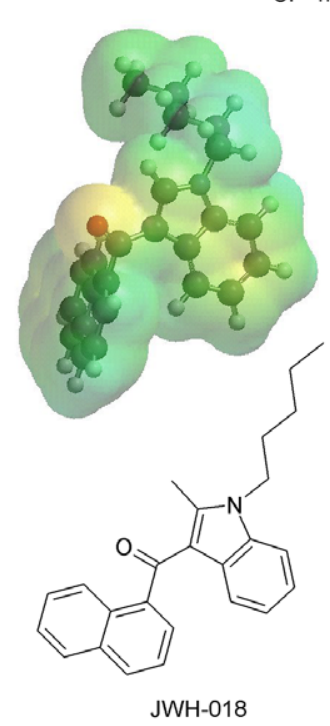


functioning of the endogenous cannabinoid system (i.e., a system that communicates through use of cannabinoids that are synthesized in the body) and may assist in more precise design of medications that can be used to treat disruptions of normal functioning of this system.

Ironically, one of the goals of Huffman's later program of research on indole-derived cannabinoids was to develop compounds that selectively activated $\mathrm{CB}_{2}$ receptors (Huffman, 2000). (THC binds to both types of receptors [Showalter, Compton, Martin, \& Abood, 1996].) Selective $\mathrm{CB}_{2}$ receptor agents would have potential use as anti-inflammatory analgesics and would not be expected to produce marijuana-like intoxication (Patel, Davison, Pittman, \& Sharkey, 2010). The potential effects of this aspect of the pharmacology of indole-derived synthetic cannabinoids on peripheral physiological systems of abusers, however, are unknown and have received even less research than their centrally mediated effects.

Such is the foundation of basic science: hypothesis generation and testing followed by publication of the results. Although interdisciplinary cooperation that is the hallmark of basic and clinical research today was key to the long-standing collaboration between the groups at Clemson and VCU, possible clinical implications of the basic science research that resulted in development of JWH cannabinoids were usually confined to a few concluding sentences in each publication.

However, the fact that people are now abusing JWH cannabinoids has taken cannabinoid research to the public marketplace without the aid of clinical trials or regulatory oversight, with currently unknown implications for human health and behavior. Furthermore, it has primed the area for initiation of additional research, garnering the attention of researchers who heretofore had never read any of the original publications on indole-derived cannabinoids. Interestingly, the compounds that have been appearing in herbal products are those with the best $\mathrm{CB}_{1}$ receptor affinities, suggesting that the suppliers of these products have been reading the scientific literature to determine which compounds are most likely to produce the effect of interest (intoxication) with the least likelihood of adverse effects (e.g., law enforcement interference). Indeed, perusal of the scientific literature is the likely method through which illicit manufacturers of synthetic cannabinoids discovered their existence and potential abuse liability.

\section{Previous Cases of Designer Drugs}

This situation is not the first-nor the last (e.g., witness the recent emergence of products containing cathinone analogs, stimulants that have been marketed as "bath salts" or "plant food")_instance where research on novel synthetic drugs conducted by legitimate scientists, often with support from the National Institutes of Health, has led to compounds that have subsequently been subject to abuse.

The phenethylamine analogs of mescaline and amphetamine and the tryptamine analogs of LSD became known as "designer drugs" because they were made and abused prior to their regulatory control, often for many years (Shulgin \& Shulgin, 1991, 1997). Indeed, people used one of these designer drugs, methylenedioxymethamphetamine (MDMA, or ecstasy), for years before it became illegal. Another interesting example is the drug phencyclidine (PCP). Although abuse reports did not begin until the early 1970s, the street name, PCP, was based on an abbreviation for the chemical name 1-(1-phenylcyclohexyl) piperidine that was published over 10 years earlier (Chen, Ensor, Russell, \& Bohner, 1959).

\section{Clinical Effects of Synthetic Cannabinoids}

Although researchers have not conducted systematic studies of the clinical effects of synthetic cannabinoids, anecdotal reports and case studies (primarily from visits to the emergency room) reveal that many, but not all, of the effects of synthetic cannabinoids resemble those of marijuana. Similar effects include subjective intoxication, tachycardia (fast pulse rate), and conjunctival injection (red eyes) (Auwarter et al., 2009). In addition, at least one case study has been published that documents dependence and associated withdrawal in an individual following 
chronic (8 month) use of synthetic cannabinoids (Zimmermann et al., 2009).

According to some reports, the intoxication produced by synthetic cannabinoids is more intense than that produced by cannabis, while others report that it is milder (Vardakou, Pistos, \& Spiliopoulou, 2010). Previous findings that WIN 55,212-2 and some indole-derived synthetic cannabinoids have better affinity for the $\mathrm{CB}_{1}$ receptor and may activate it more strongly (i.e., have higher efficacy) than THC (Atwood, Huffman, Straiker, \& Mackie, 2010; Griffin, Atkinson, Showalter, Martin, \& Abood, 1998; Huffman et al., 2005) are consistent with the idea that synthetic cannabinoids have greater potency in vivo than marijuana; hence, people smoking either marijuana or herbal incense with an identical amount of active cannabinoid (THC or synthetic) would be expected to show greater intoxication with synthetic cannabinoids such as JWH-018 and JWH-073.

In addition, studies have reported a few differences in the clinical effects of THC and synthetic cannabinoids. Whereas marijuana tends to decrease blood pressure, individuals smoking herbal incense with synthetic cannabinoids have had high blood pressure upon admission to the emergency department. Other symptoms that tend to be more pronounced in users of synthetic cannabinoids include increased anxiety or agitation (Schneir, Cullen, \& Ly, 2010), nausea and vomiting (Schifano et al., 2009), and psychiatric disturbance (e.g., suicidality, exacerbation of preexisting psychosis) (Every-Palmer, 2011; Müller et al., 2010).

Several caveats apply to these observations. First, many published reports on the clinical effects of synthetic cannabinoids derive primarily from persons seeking treatment in a hospital emergency department. Consequently, effects that are described may be characteristic of only the most severe cases of intoxication. Second, published reports have not always verified the content and purity of the synthetic cannabinoids contained in herbal incense. In addition, studies have neither identified other substances in the plant material of the incense product nor evaluated their potential contribution to intoxication (or to modulation of the effects of synthetic cannabinoids).

\section{Research Needed}

Formulation of a workable solution for handling the issue of abuse of non-controlled synthetic cannabinoids or herbal products containing them will require collaborative input from all interested parties, including basic and clinical scientists, legislative bodies, regulatory agencies, parents, and other concerned citizens. Like the creation of the problem itself, the foundation of its solution starts with science. Despite increasing incidence of use of synthetic cannabinoids, no controlled clinical studies have examined their pharmacological effects in humans, and research on their behavioral effects in animals is sparse, with only a few studies that have examined the acute in vivo effects of a small percentage (less than 10 percent) of the entire series of over 200 indole- and pyrrole-derived cannabinoids synthesized in Huffman's lab (Huffman, Dai, Martin, \& Compton, 1994; Vann et al., 2009; Wiley et al., 1998; Wiley, Huffman, Balster, \& Martin, 1995), not to mention synthetic cannabinoids developed by other researchers.

Anecdotal reports from users of these herbal products suggest identifiable differences in the degree of intoxication, dependent upon the "flavor" (and presumably upon the specific synthetic cannabinoids contained therein). Research is needed to learn more about the possibly subtle differences in the effects of these synthetic cannabinoids and/or in the various plant materials upon which the chemicals are sprayed. Indeed, to preemptively control some of these products instead of reacting to abuse situations after they occur, regulatory authorities need data on the chemistry and pharmacology of cannabinoids receptor agonists.

Efficient forensic methods for detection of the numerous cannabinoid variants contained in the herbal products and their probable metabolites are also lacking (Dresen et al., 2010). Collaborative work among scientists and researchers to examine the effects of these synthetic compounds in animals and in human users would provide health care workers with additional information on potential impact of acute and repeated use of these substances on health, including addiction, and would give policy makers a 
scientific basis for regulation of the content of these potent products.

In the process of this work, comparison of synthetic cannabinoids or herbal preparations with their closest referents, THC or marijuana, will be essential. Coincidentally, simultaneous with the appearance of these herbal products, several states were challenging the legal status of marijuana. Although California voters recently rejected a proposition to legalize recreational use of marijuana, decriminalization remains the trend there and in some, but not all, other states. In addition, prescription of marijuana for medicinal purposes is widespread in California and some other states. Examining comparative prevalence of marijuana use versus use of synthetic cannabinoid herbal preparations across states and globally, particularly data from the period when these herbal products still served as a legal alternative to marijuana, would present a potentially valuable source of information on the effects of different regulatory approaches on demand of these formulations.

In fact, although little is known about the extent to which smoking mixtures containing synthetic cannabinoids has replaced cannabis smoking in the United States or globally, a preliminary survey conducted among 1,463 students aged 15 to 18 years at schools providing general and vocational training in Frankfurt, Germany, found that around 6 percent of respondents reported having used Spice at least once (EMCDDA, 2009). Determining the extent to which the population of users of synthetic cannabinoids overlaps with that of marijuana users would indicate whether the availability of these products serves as an incentive to a new group of substance abusers or is primarily an alternative for marijuana smokers.

\section{Concluding Remarks}

While it is too soon to discern the overall public health impact of the abuse of synthetic cannabinoids, previous experience with other designer drugs shows that making synthetic drugs illegal does not prevent them from being made and abused. In addition, many hundreds of other compounds that could have cannabimimetic effects are not yet specifically regulated, so some of them may factor in as well. We may be on the verge of another ecstasy-like problem, although the relatively easy availability of natural cannabis products worldwide may make abuse of synthetic cannabinoids less profitable.

On the other hand, it is interesting to note that the advertized price of these synthetic herbal mixtures on the Internet of $\$ 10$ to $\$ 12$ per gram is about the same as typical prices for high-quality medical marijuana sold in legal dispensaries, so if the price of legally obtainable cannabis products remains high, a market for these synthetic variants may remain. Most important is the need for scientific investigation of the health consequences of synthetic cannabinoid abuse.

\section{References}

Atwood, B. K., Huffman, J., Straiker, A., \& Mackie, K. (2010). JWH018, a common constituent of 'Spice' herbal blends, is a potent and efficacious cannabinoid CB receptor agonist. British Journal of Pharmacology, 160(3), 585-593.

Aung, M. M., Griffin, G., Huffman, J. W., Wu, M., Keel, C., Yang, B., ... Martin, B. R. (2000). Influence of the $\mathrm{N}-1$ alkyl chain length of cannabimimetic indoles upon $\mathrm{CB}(1)$ and $\mathrm{CB}(2)$ receptor binding. Drug and Alcohol Dependence, 60(2), 133-140.
Auwarter, V., Dresen, S., Weinmann, W., Muller, M., Putz, M., \& Ferreiros, N. (2009). 'Spice' and other herbal blends: Harmless incense or cannabinoid designer drugs? Journal of Mass Spectrometry, 44(5), 832-837.

Chen, G., Ensor, C. R., Russell, D., \& Bohner, B. (1959). The pharmacology of 1-(1-phenylcyclohexyl) piperidine HCl. Journal of Pharmacology and Experimental Therapeutics, 127, 241-250. 
Compton, D. R., Gold, L. H., Ward, S. J., Balster, R. L., \& Martin, B. R. (1992). Aminoalkylindole analogs: cannabimimetic activity of a class of compounds structurally distinct from delta-9-tetrahydrocannabinol. Journal of Pharmacology and Experimental Therapeutics, 263(3), 1118-1126.

Cox, A. O., Daw, R. C., Mason, M. D., Grabenauer, M. A., Pande, P. G., Davis, K. H., ... Thomas, B. F. (In press). Use of SPME-HS-GC/ MS for analysis of herbal products containing synthetic cannabinoids or other illicit substances. Journal of Analytical Toxicology.

D’Ambra, T. E., Estep, K. G., Bell, M. R., Eissenstat, M. A., Josef, K. A., Ward, S. J., ... Daley, G. T. (1992). Conformationally restrained analogues of pravadoline: nanomolar potent, enantioselective, (aminoalkyl)indole agonists of the cannabinoid receptor. Journal of Medicinal Chemistry, 35(1), 124-135.

Devane, W. A., Dysarz, F. A., Johnson, M. R., Melvin, L. S., \& Howlett, A. C. (1988). Determination and characterization of a cannabinoid receptor in rat brain. Molecular Pharmacology, 34, 605-613.

Dresen, S., Ferreiros, N., Putz, M., Westphal, F., Zimmermann, R., \& Auwarter, V. (2010). Monitoring of herbal mixtures potentially containing synthetic cannabinoids as psychoactive compounds. Journal of Mass Spectrometry, 45(10), 1186-1194.

Eissenstat, M. A., Bell, M. R., D’Ambra, T. E., Alexander, E. J., Daum, S., Ackerman, J., ... Ward, S. J. (1995). Aminoalkylindoles: Structure-activity relationships of novel cannabinoid mimetics. Journal of Medicinal Chemistry, 38, 3094-3105.

European Monitoring Centre for Drugs and Drug Addiction (EMCDDA). (2009). EMCDDA 2009 thematic paper-Understanding the 'Spice' phenomenon. Luxembourg: Office for Official Publications of the European Communities. Available from http://www.emcdda.europa.eu/ attachements.cfm/att_80086_EN_Spice\%20 Thematic\%20paper\%20-\%20final\%20version.pdf
Everett, R. M., Descotes, G., Rollin, M., Greener, Y., Bradford, J. C., Benziger, D. P., ... Ward, S. J. (1993). Nephrotoxicity of pravadoline maleate (WIN 48098-6) in dogs: evidence of maleic acidinduced acute tubular necrosis. Fundamentals of Applied Toxicology, 21, 59-65.

Every-Palmer, S. (2011). Synthetic cannabinoid JWH-018 and psychosis: An explorative study. Drug and Alcohol Dependence, 117, 152-157.

Griffin, G., Atkinson, P. J., Showalter, V. M., Martin, B. R., \& Abood, M. E. (1998). Evaluation of cannabinoid receptor agonists and antagonists using the guanosine-5'-O-(3-[35S] thio)triphosphate binding assay in rat cerebellar membranes. Journal of Pharmacology and Experimental Therapeutics, 285, 553-560.

Haubrich, D. R., Ward, S. J., Baizman, E., Bell, M. R., Bradford, J., Ferrari, R., ... Luttinger, D. (1990). Pharmacology of pravadoline: A new analgesic agent. Journal of Pharmacology and Experimental Therapeutics, 255(2), 511-522.

Huestis, M. A., Gorelick, D. A., Heishman, S. J., Preston, K. L., Nelson, R. A., Moolchan, E. T., ... Frank, R. A. (2001). Blockade of effects of smoked marijuana by the CB1-selective cannabinoid receptor antagonist SR141716. Archives of General Psychiatry, 58(4), 322-328.

Huffman, J. W. (2000). The search for selective ligands for the CB2 receptor. Current Pharmaceutical Design, 6(13), 1323-1337.

Huffman, J. W., Dai, D., Martin, B. R., \& Compton, D. R. (1994). Design, synthesis and pharmacology of cannabimimetic indoles. Bioorganic and Medicinal Chemistry Letters, 4(4), 563-566.

Huffman, J. W., Szklennik, P. V., Almond, A., Bushell, K., Selley, D. E., He, H., ... Martin, B. R. (2005). 1-Pentyl-3-phenylacetylindoles, a new class of cannabimimetic indoles. Bioorganic and Medicinal Chemistry Letters, 15(18), 4110-4113.

Lainton, J. A. H., Huffman, J. W., Martin, B. R., \& Compton, D. R. (1995). 1-Alkyl-3-(1-naphthoyl) pyrroles: A new cannabinoid class. Tetrahedron Letters, 36(9), 1401-1404. 
Lindigkeit, R., Boehme, A., Eiserloh, I., Luebbecke, M., Wiggermann, M., Ernst, L., \& Beuerle, T. (2009). Spice: A never ending story? Forensic Science International, 191(1-3), 58-63.

L.P.O.E., Inc. v. U.S. Drug Enforcement Admin., No. 10-CV-4944 (PJS/LIB) (D. Minn. filed Dec. 21, 2010).

Martin, B. R., Compton, D. R., Thomas, B. F., Prescott, W. R., Little, P. J., Razdan, R. K., ... Ward, S. J. (1991). Behavioral, biochemical, and molecular modeling evaluations of cannabinoid analogs. Pharmacology Biochemistry and Behavior, 40, 471-478.

Müller, H., Sperling, W., Köhrmann, M., Huttner, H. B., Kornhuber, J., \& Maler, J.-M. (2010). The synthetic cannabinoid Spice as a trigger for an acute exacerbation of cannabis induced recurrent psychotic episodes. Schizophrenia Research, 118, 309-310.

Patel, K. D., Davison, J. S., Pittman, Q. J., \& Sharkey, K. A. (2010). Cannabinoid CB(2) receptors in health and disease. Current Medicinal Chemistry, 17(14), 1393-1410.

Schifano, F., Corazza, O., Deluca, P., Davey, Z., Di Furia, L., Farre, M., ... Van Der Kreeft, P. (2009). Psychoactive drug or mystical incense? Overview of the online available information on Spice products. International Journal of Culture and Mental Health, 2, 137-144.

Schneir, A. B., Cullen, J., \& Ly, B. T. (2010). "Spice” girls: Synthetic cannabinoid intoxication. Journal of Emergency Medicine, 40, 296-299.

Showalter, V., Compton, D. R., Martin, B. R., \& Abood, M. E. (1996). Evaluation of binding in a transfected cell line expressing a peripheral cannabinoid receptor $\left(\mathrm{CB}_{2}\right)$ : Identification of cannabinoid receptor subtype selective ligands. Journal of Pharmacology and Experimental Therapeutics, 278, 989-999.

Shulgin, A., \& Shulgin, A. (1991). PiHKAL: A chemical love story. Berkeley, CA: Transform Press.
Shulgin, A., \& Shulgin, A. (1997). TiHKAL: The continuation. Berkeley, CA: Transform Press.

Teske, J., Weller, J. P., Fieguth, A., Rothamel, T., Schulz, Y., \& Troger, H. D. (2010). Sensitive and rapid quantification of the cannabinoid receptor agonist naphthalen-1-yl-(1-pentylindol-3-yl) methanone (JWH-018) in human serum by liquid chromatography-tandem mass spectrometry. Journal of Chromatography B: Analytical Technologies in the Biomedical and Life Sciences, 878, 2659-2663.

Thomas, B. F., Compton, D. R., Martin, B. R., \& Semus, S. F. (1991). Modeling the cannabinoid receptor: A three-dimensional quantitative structure-activity analysis. Molecular Pharmacology, 40, 656-665.

Uchiyama, N., Kikura-Hanajiri, R., Ogata, J., \& Goda, Y. (2010). Chemical analysis of synthetic cannabinoids as designer drugs in herbal products. Forensic Science International, 198(1-3), 31-38.

Vann, R. E., Warner, J. A., Bushell, K., Huffman, J. W., Martin, B. R., \& Wiley, J. L. (2009). Discriminative stimulus properties of delta-9tetrahydrocannabinol (THC) in C57Bl/6J mice. European Journal of Pharmacology, 615(1-3), 102-107.

Vardakou, I., Pistos, C., \& Spiliopoulou, C. (2010). Spice drugs as a new trend: Mode of action, identification and legislation. Toxicology Letters, 197(3), 157-162.

Wiley, J., Lowe, J., Balster, R., \& Martin, B. (1995). Antagonism of the discriminative stimulus effects of delta-9-tetrahydrocannabinol in rats and rhesus monkeys. Journal of Pharmacology and Experimental Therapeutics, 275(1), 1-6.

Wiley, J. L., Compton, D. R., Dai, D., Lainton, J. A., Phillips, M., Huffman, J. W., \& Martin, B. R. (1998). Structure-activity relationships of indoleand pyrrole-derived cannabinoids. Journal of Pharmacology and Experimental Therapeutics, 285(3), 995-1004. 
Wiley, J. L., Huffman, J. W., Balster, R. L., \&

Martin, B. R. (1995). Pharmacological specificity of the discriminative stimulus effects of delta 9-tetrahydrocannabinol in rhesus monkeys. Drug and Alcohol Dependence, 40(1), 81-86.
Zimmermann, U. S., Winkelmann, P. R., Pilhatsch, M., Nees, J. A., Spanagel, R., \& Schulz, K. (2009). Withdrawal phenomena and dependence syndrome after the consumption of "spice gold." Deutsches Ärzteblatt International, 106(27), 464-467. 


\section{Acknowledgments}

Preparation of this manuscript was supported in part by National Institute on Drug Abuse grants DA-031988 and DA-03672. 
RTI International is an independent, nonprofit research organization dedicated to improving the human condition by turning knowledge into practice. RTI offers innovative research and technical solutions to governments and businesses worldwide in the areas of health and pharmaceuticals, education and training, surveys and statistics, advanced technology, international development, economic and social policy, energy and the environment, and laboratory and chemistry services.

The RTI Press complements traditional publication outlets by providing another way for RTI researchers to disseminate the knowledge they generate. This PDF document is offered as a public service of RTI International. 